\title{
Lingual and Mediastinal Ectopic Thyroid with No Normal Thyroid Gland - A Very Rare Occurrence
}

\author{
Shyam Kalyan N, ${ }^{1}$ Deepjoy Basu, ${ }^{1}$ Mehak Agarwal, ${ }^{1}$ Dulal Bose ${ }^{1}$
}

\section{Introduction}

\section{ABSTRACT}

Ectopic thyroid is a rare congenital condition. Dual ectopic thyroid is rarer still with only 30 cases reported in literature. The most common location is the lingual or sublingual region followed by the hyoid region. Instances of dual ectopic thyroid with one in lingual region and the other in mediastinum are very few.

Case Report

A case of dual ectopic thyroid is presented with absent normal thyroid in a girl of 14 years who presented with difficulty in swallowing and lump sensation in throat. Ultrasound, MRI scan and Technetium $99 \mathrm{~m}$ pertechnetate thyroid scan were done. She showed lingual thyroid and thyroid tissue in upper mediastinum and no thyroid tissue in the normal anatomical location.

Discussion

The discovery of mediastinal ectopic thyroid was incidental. She had subclinical hypothyroidism and was treated with thyroxine replacement therapy.

Keywords

Thyroid Dysgenesis; Ectopic Thyroid Tissue; Mediastinum; Lingual thyroid

$\mathrm{E}$ ctopic thyroid tissue (ETT) is a rare congenital anomaly where one finds thyroid tissue in areas other than its normal location, that is, anterior to second to fourth tracheal cartilages. The prevalence of ETT is reported to be 1 per 100000 to 300000 individuals. ${ }^{1}$ ETT occurs due to stunted descent of median or lateral thyroid anlage. These are usually found in the midline of anterior neck. It is still rarer to find ectopic thyroid simultaneously at two different locations. ${ }^{2}$ The most common location of ETT is the base of tongue. The lingual thyroid may be the only functioning gland in about $70 \%$ of the ectopic thyroid cases. ${ }^{3}$ The next common location is the hyoid region. Most of the patients are adolescents and frequently present with swelling in the anterior neck or in the tongue with or without altered hormonal status. Only a few cases of dual ectopic thyroid have been documented in the literature. Such a case with an ectopic in mediastinum as well as one in the lingual region with absent normal thyroid has not been reported. Here we report a case of a 14 year old girl who was diagnosed to have dual ectopic thyroid at lingual and mediastinal sites with no thyroid tissue at the normal anatomical location. The diagnosis was aided by ultrasonography, MRI scan and Tc-99m pertechnetate thyroid scan.

\section{Case Report}

A 14 year old girl presented to our out-patient department with complaints of foreign body sensation in throat and difficulty in swallowing for the last 2 years. There was a recent worsening of symptoms over the past few months. There was no difficulty in breathing or any symptom of thyroid dysfunction. On clinical examination the girl had a well-defined, smooth, globular mass, about $2 \mathrm{~cm} \times 2 \mathrm{~cm}$ in size,

1 - Department of ENT, Peerless Hospital, Kolkata

Corresponding author:

Dr Shyam Kalyan N

email: shyamkal87@gmail.com 


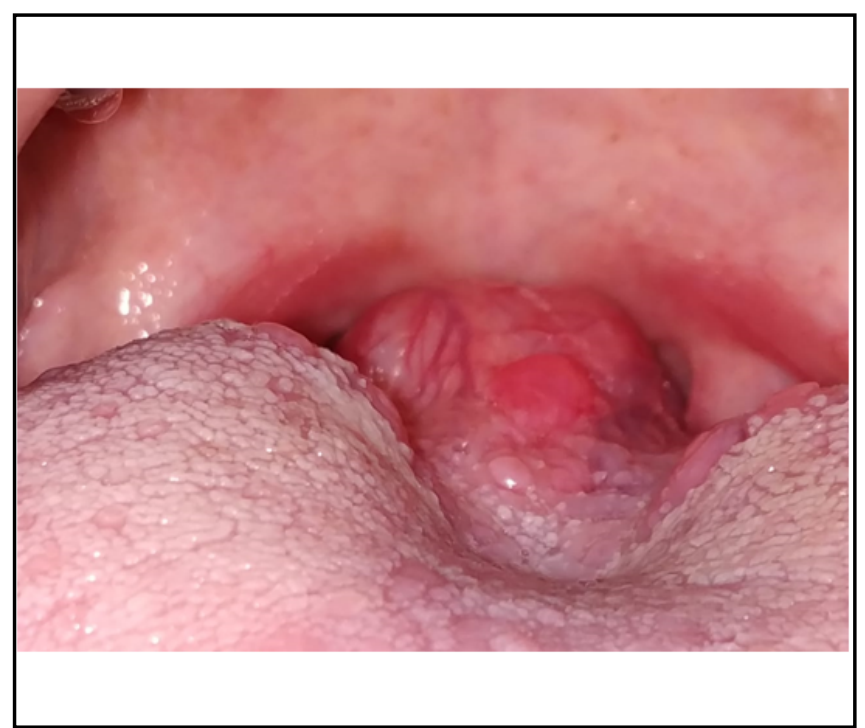

Fig. 1. A well-defined smooth, globular mass of size $2 \times 2 \mathrm{~cm}$ in the posterior one-third of tongue.

in the posterior one-third of tongue (Fig. 1). Neck examination was normal with no palpable node.

Ultrasound of neck showed a $21 \mathrm{~mm}$ x $19 \mathrm{~mm}$ hypoechoic rounded lesion at the base of tongue with internal vascularity (Fig. 2). The thyroid fossa was noted to be empty. MRI neck and thorax confirmed the findings of ultrasound and showed another soft tissue focus in upper mediastinum with right and left components, measuring $20 \mathrm{~mm} \times 15 \mathrm{~mm}$ and $20 \mathrm{~mm} \times 10 \mathrm{~mm}$ respectively, with central confluence (Fig. 3 and Fig. 4). The thyroid fossa was noted to be empty with no evidence of normal thyroid tissue within it in the MRI as well.

The biochemical parameters were suggestive of subclinical hypothyroidism, with T3- $160 \mathrm{ng} / \mathrm{dL}$ (normal being 60 to $185 \mathrm{ng} / \mathrm{dL}$ ), T4-11 $\mathrm{mcg} / \mathrm{dL}$ (normal being 4.8 to $12 \mathrm{mcg} / \mathrm{dL}$ ) and TSH-6.4 microIU $/ \mathrm{mL}$ (normal being 0.3 to $5.5 \mathrm{microIU} / \mathrm{mL}$ ).

Technetium $99 \mathrm{~m}$ pertechnetate thyroid scan with $2 \mathrm{mCi}(74 \mathrm{MBq})$ showed no trapping of isotope in the normal pre-tracheal position of thyroid and an increased uptake in the lingual and upper mediastinal regions, suggestive of dual ectopic thyroid. The patient was treated conservatively with thyroid replacement therapy to reduce the size of the ectopic thyroid tissues and followed up with clinical examination for decrease in the size of the swelling and thyroid function tests to check the euthyroid status.

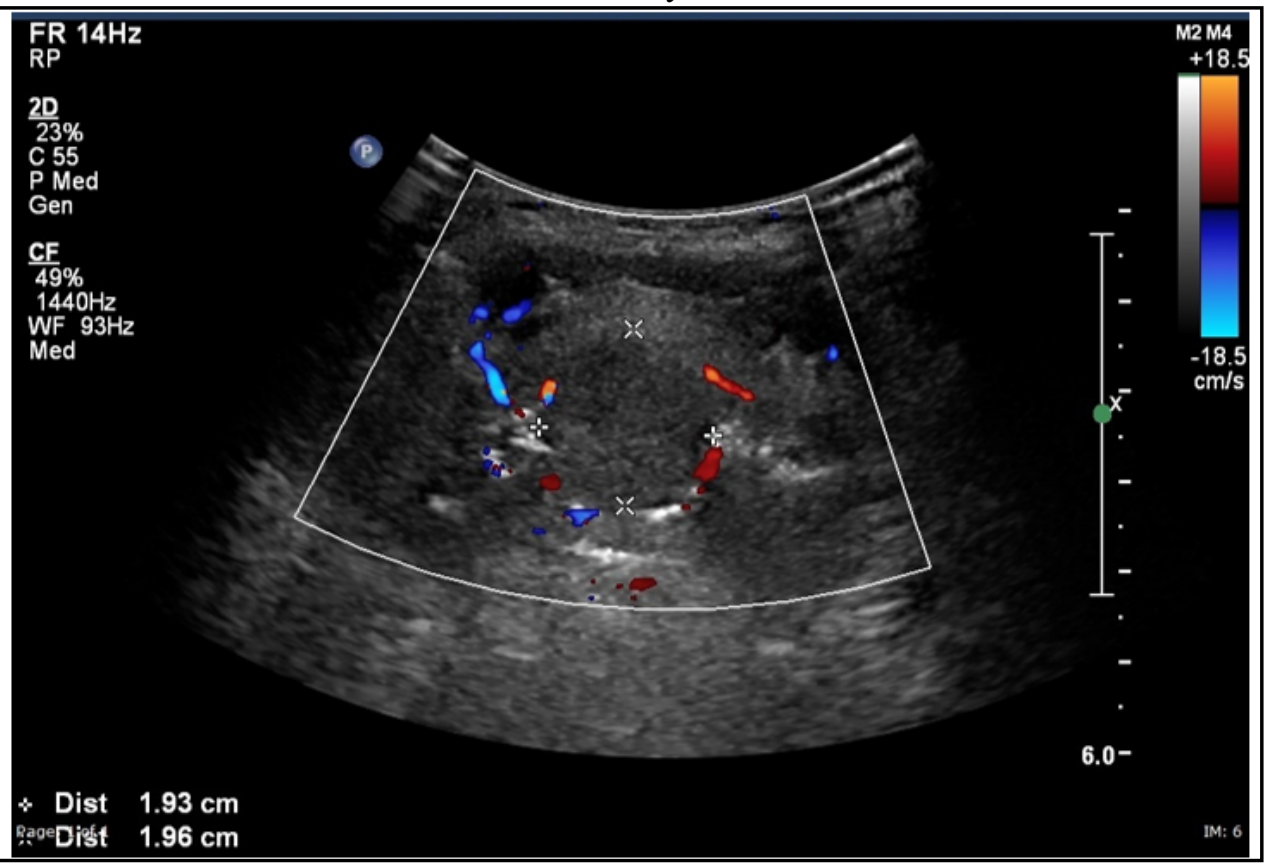

Fig. 2. A well-defined hypoechoic nodule with internal vascularity in the base of tongue. 


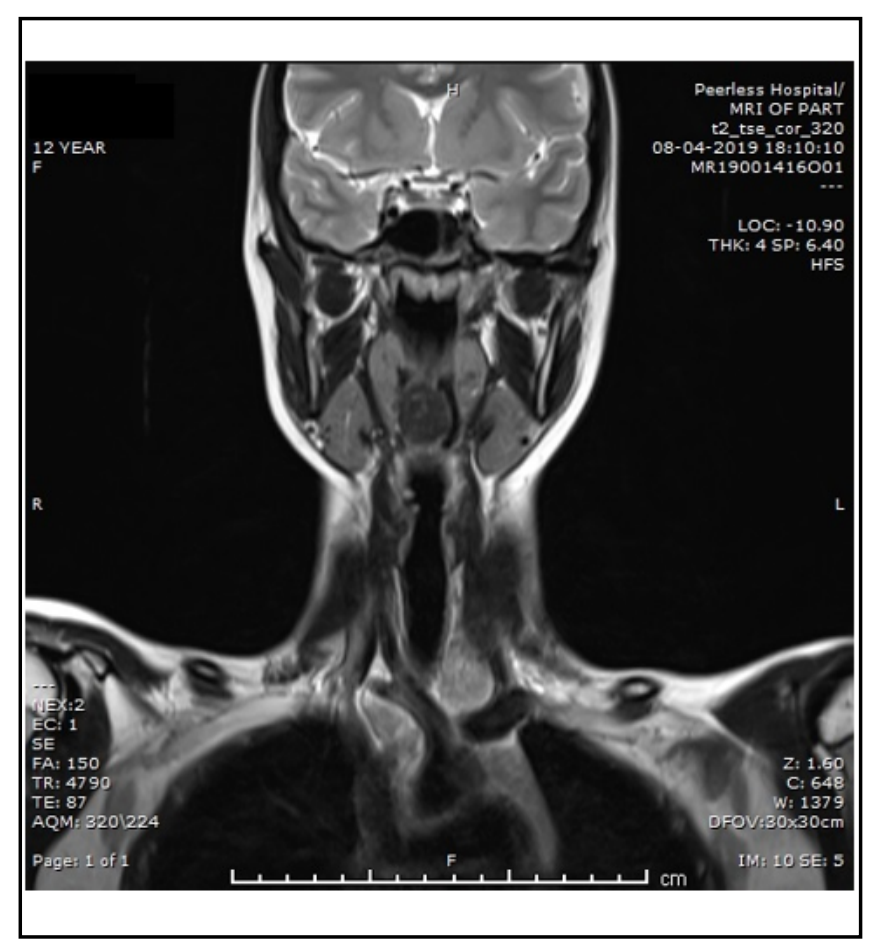

Fig. 3. T2 Coronal images showing hypointense nodule in the base of tongue. Hyperintense nodules are seen in the superior mediastinum. The one on the right is inferolateral to the innominate artery and the one on left is superomedial to the left brachiocephalic vein.

\section{Discussion}

Ectopic thyroid tissue (ETT) is any thyroid tissue that is not found in relation to the anterolateral aspect of second to fourth tracheal rings. It occurs due to the failure of descent of thyroid tissue from the foramen caecum to the normal location in the cervical region in front of trachea. It occurs more commonly in females and becomes evident during adolescence or pregnancy as the requirement for thyroid hormone increases during this period. ${ }^{4}$ Most patients with dual ectopic thyroid seek medical help between the ages of 11 and 28 years. ${ }^{2}$ The production from ectopic tissues is insufficient leading to subclinical or clinical hypothyroidism. This causes increased secretion of TSH from the pituitary leading to stimulation of follicular cells

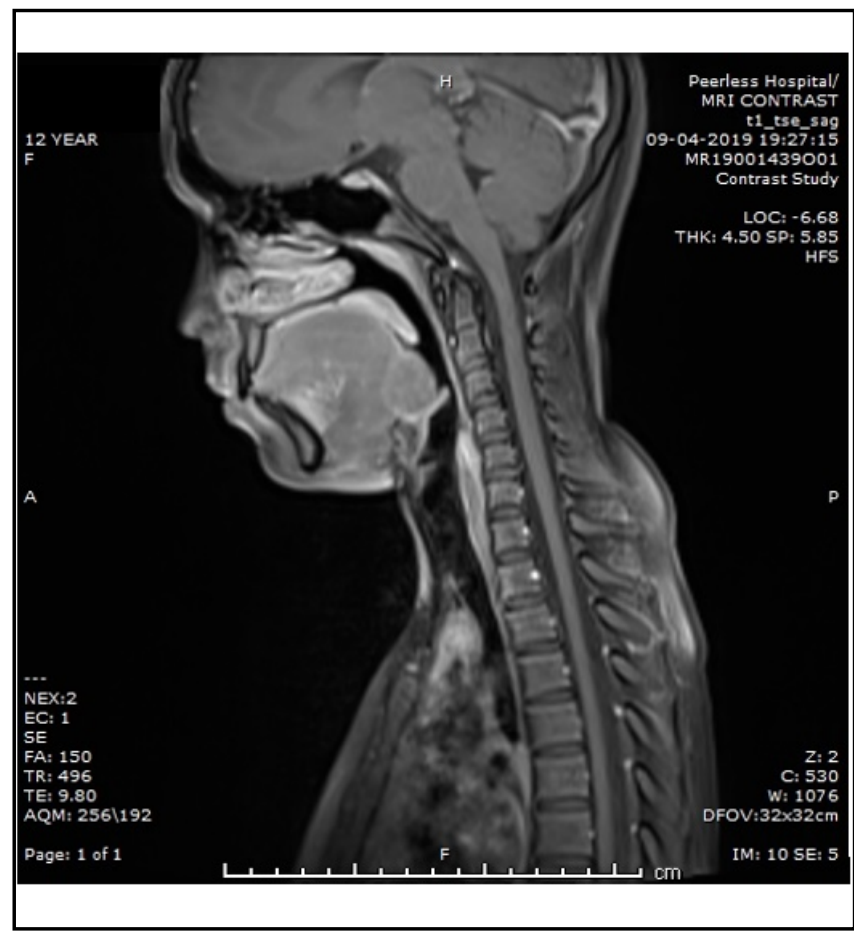

Fig. 4. Sagittal T1 fat saturated (post contrast) cut showing an uniformly enhancing nodule in the base of tongue, at the level of the foramen caecum. It splays the vallecula. There is a hypointense nonenhancing midline tract extending from the inferior aspect of the nodule probably a fibrous tract. No thyroid tissue is seen anterior to the trachea. Isolated enhancing soft tissue nodule is seen in the base of the neck, extending into the retromanubrial space.

of the ectopic tissue resulting in its increased size. The symptoms caused can vary depending on the location of the ETT.

Most reported cases of dual ectopic thyroid have one site of ectopy in the lingual or sublingual region and the second site at subhyoid or suprahyoid level. It is extremely rare to find the second site of ectopy in upper mediastinum, as in our case. As seen in most of the cases of dual ectopic thyroid, our case also did not have normal thyroid gland. In most of the cases, the diagnosis of dual ectopic thyroid is made on thyroid scan, though ultrasound and CT scan are additional imaging modalities in some of the cases. $^{5}$

All diseases capable of affecting the thyroids 
can affect the ectopic thyroid tissue as well, like hyperplasia, adenoma, inflammation and malignancy. Carcinoma of lingual thyroid is reported to have an incidence of $1 \%$ with follicular variant being the commonest. ${ }^{6}$

Lifelong thyroxine therapy is usually given to reduce the size of the ectopic thyroid by lowering the TSH level as well as achieving euthyroid status. Asymptomatic and euthyroid patients may be just observed without any treatment. Surgery is reserved for those cases where the obstructive or pressure symptoms are severe or there is suspicion of or proven malignancy in the ETT. ${ }^{7}$ Surgery may remove the only functioning thyroid tissue in the body and so one has to be cautious before deciding on surgery for a patient.

Benign mediastinal ETT is usually asymptomatic and discovered incidentally. It may be excised to diagnose the nature of the mass as there is a risk of tracheal compression due to haemorrhage within or malignant transformation of the mass. ${ }^{8}$ A mediastinal ectopic thyroid mass may need thoracotomy or sternotomy for surgical excision.

In our case the young girl presented with a symptomatic lingual swelling and the discovery of mediastinal ectopic tissue was incidental. She was given thyroxine replacement therapy and is being followed up regularly.

\section{References}

1. Guerra G, Cinelli M, Mesolella M, TafuriD, etal. Morphological, diagnostic and surgical features of ectopic thyroid gland: A review of literature. Int J Surg. 2014; 12 Supplement 1:S3-S11

2. Meng Z, Lou S, Tan J, Jia Q, et al. Scintigraphic detection of dual ectopic thyroid tissue: Experience of a Chinese tertiary hospital. PLoS ONE 2014 Apr18; 9(4):e95686. DOI: 10.1371/ journal.pone.0095686

3. Raza SA, Saldanha M, Nagalotimath US, Ponni SA. Dual ectopic thyroid. Natl J Otorhinolaryngol Head Neck Surg. 2013; 1:26-7

4. Kumar R, Sharma S, Marwah A, Moorthy D, Dhanwal D, Malhotra A. Ectopic goiter masquerading as submandibular gland swelling: A case report and review of the literature. Clin Nucl Med. 2001 Apr; 26(4):306-9

5. Sood A, Sood V, Sharma DR, Seam RK, Kumar R. Thyroid scintigraphy in detecting dual thyroid: A review. Eur J Nucl Med Mol Imaging 2008 Apr; 35(4):843-6

6. Jarvis JF. Lingual thyroid: A report of three cases and discussion. S Afr Med J. 1969 Jan 04; 43(1):812

7. Giannoulis G, Manolidi L, Grammaticos P. A case of sublingual thyroid partially implanted in the left iliac fossa. Hell Iatr. 1968; 40:1175-81

8. Choudhury BK, Saikia UK, Sarma D, Saikia M, et al. Dual ectopic thyroid with normally located thyroid: A case report. J. Thyroid Res. 2011; 2011:159703. Available from: https:// www.hindawi.com/journals/jtr/2011/159703/ 